\title{
Kidney Transplantation from Donors with Severe Disseminated Intravascular Coagulation
}

\author{
Lena Sibulesky, Reginald Gohh, Kevin Charpentier, and Paul Morrissey \\ Division of Organ Transplantation, Rhode Island Hospital, Alpert Medical School, Brown University, 593 Eddy Street, \\ APC 921, Providence, RI 02903, USA \\ Correspondence should be addressed to Paul Morrissey; pmorrissey@lifespan.org
}

Received 31 December 2012; Accepted 30 January 2013

Academic Editors: W. Lim, J. M. Rebibou, A. Rydzewski, and M. Veroux

Copyright (C) 2013 Lena Sibulesky et al. This is an open access article distributed under the Creative Commons Attribution License, which permits unrestricted use, distribution, and reproduction in any medium, provided the original work is properly cited.

Disseminated intravascular coagulation (DIC) is a syndrome characterized by massive formation of thrombin, which can lead to renal dysfunction or failure. Many transplant centers are reluctant to accept the kidneys from donors with DIC especially if renal dysfunction is present. We developed protocol of machine perfusion followed by tissue plasminogen activator (tPA) infusion in order to treat and evaluate DIC kidneys prior to transplantation. The kidneys were placed on machine preservation with tPA added to the perfusate prior to transplantation. Three kidneys were transplanted from two donors who sustained gunshot injuries to the brain. A biopsy at the time of organ recovery documented widespread fibrin thrombi in approximately $80 \%$ of the glomeruli. Serial biopsies showed interval improvement following machine perfusion and a normal appearing kidney three months after successful transplantation. The histological presence of DIC in a deceased organ donor, even if associated with renal dysfunction, is not a contraindication to renal transplantation. Machine perfusion and tPA infusions may contribute to the recovery and successful transplantation of such kidneys.

\section{Introduction}

In the 1970s, several authors observed an association of traumatic brain injury and disseminated intravascular coagulation (DIC), a syndrome characterized by massive formation of thrombin $[1,2]$. When the circulation is exposed to large amounts of tissue factor, coagulopathy may develop resulting in widespread deposition of intravascular fibrin and ultimately leading to thrombosis of small and midsize vessels. The spectrum of DIC can range from laboratory abnormalities of no clinical significance, including decrease in platelet count and prolongation of clotting time, to fulminant activation of clotting cascade with multiple organ failure [3]. Clinical manifestations of DIC are variable and may include petechiae, purpura and other signs of abnormal bleeding, fever, hypotension, proteinuria, and hypoxia. Microvascular thrombosis can result in cardiac, pulmonary, renal, hepatic, and CNS dysfunction [4].

Establishing the diagnosis of DIC is problematic. The subcommittee on DIC of the International Society of Haemostasis and Thrombosis (ISHT) defined DIC as an acquired syndrome characterized by the intravascular activation of coagulation with loss of localization arising from different causes. It can originate from and cause damage to the microvasculature, which if sufficiently severe can produce organ dysfunction. The ISHT further proposed a simple scoring algorithm using the platelet count, a prolongation of the prothrombin time, a decreased fibrinogen, and plasma levels of a fibrin-related marker, such as D-dimer or other fibrin degradation products [5]. As a result of inconsistent definitions of DIC, the condition is diagnosed in as many as $29 \%$ of all organ donors [6]; however, potential organ donors with DIC as defined by the presence of coagulopathy, glomerular microthrombi, and organ dysfunction are uncommon.

Renal dysfunction may develop secondary to DIC and on occasion recovery is possible with treatment of the underlying cause of DIC or specific therapies directed at the coagulopathy. A few reports in the literature describe transplantation of kidneys from organ donors with DIC [6-8]. In most of these reports DIC was not associated with renal dysfunction. For example, Hefty et al. described 
TABLE 1: Donor characteristics.

\begin{tabular}{lcc}
\hline & Initial labs & $\begin{array}{c}\text { Labs prior to organ } \\
\text { recovery }\end{array}$ \\
\hline Donor no. 1 & 1.1 & 3.5 \\
Creatinine $(\mathrm{mg} / \mathrm{dL})$ & 1.0 & 2.2 \\
PT INR & 238 & 70 \\
Platelet $\left(\mathrm{K} / \mathrm{mm}^{3}\right)$ & 13.7 & 7.4 \\
Hgb $(\mathrm{GM} / \mathrm{dL})$ & & \\
Donor no. 2 & 1.3 & 3.4 \\
Creatinine $\left(\mathrm{mg}^{3} / \mathrm{dL}\right)$ & 1.1 & 1.7 \\
PT INR & 94 & 49 \\
Platelet $\left(\mathrm{K} / \mathrm{mm}^{3}\right)$ & 11.7 & 8.6 \\
Hgb $(\mathrm{GM} / \mathrm{dL})$ & & \\
\hline
\end{tabular}

29 organ donors with hematological abnormalities suggestive of DIC; only two had abnormal renal function. Similarly, Wang et al. reported DIC in 44/162 deceased donors based on laboratory criteria. None had severe renal dysfunction (creatinine $>3.0 \mathrm{mg} / \mathrm{dL}$ ) and no biopsy data were given. In 1978 Meyers reported successful transplantation of six of nine renal allografts with DIC and histologic findings of intraglomerular fibrin deposition [9]. Delayed graft function was noted in five of six successful transplants and primary graft nonfunction complicated the other three cases. Notably, all of the kidneys came from brain dead donors with intracranial gunshot wounds. More recently, Nghiem et al. described the successful transplantation of 13/14 kidneys with similar histological findings [10]. Nonetheless, many centers are reluctant to use these kidneys.

We report the outcome of three recipients who received allografts characterized by diffuse glomerular thrombi and severe renal dysfunction. All three kidneys were treated with machine perfusion and flushed with tissue plasminogen activator (tPA) prior to successful transplantation.

\section{Methods}

2.1. Organ Donors. The kidneys were recovered from 23-yearold and 26-year-old previously healthy males who sustained a gunshot wound to the head. Both were Caucasian. One organ was recovered out-of-region and the other within our Organ Procurement Organization (OPO). Initially the kidney function was normal, but over 24 hours the creatinine steadily rose (Table 1 ), despite adequate urine output (50$100 \mathrm{cc}$ /hour). Both donors developed profound thrombocytopenia and coagulopathy suggesting DIC. Fibrinogen and fibrin degradation products were not measured. We postulated renal dysfunction secondary to DIC and confirmatory biopsies of all three kidneys were performed.

After brain death declaration and consent, organ recovery was uneventful. Wedge biopsies of the kidneys from the first donor revealed diffuse glomerular intracapillary thrombosis in 18 out of 25 glomeruli in the left kidney and 33 out of 37 glomeruli on the right. The kidney from the other donor showed diffuse petechiae throughout the kidney and fibrin thrombi in $80 \%$ of the glomeruli. There was no evidence of glomerulosclerosis, arteriosclerosis, or interstitial fibrosis in any of the kidneys.

2.2. Organ Treatment. The first donor's kidneys were imported to our institution in cold storage with University of Wisconsin solution and placed individually on the machine perfusion pump. Pump flows began at 115 and $116 \mathrm{~mL} / \mathrm{min}$ and increased over four hours to 187 and $155 \mathrm{~mL} / \mathrm{min}$, respectively. The resistive index (mean pressure/flow) for the left and right kidneys was 0.31 initially and $0.16-0.20$ after four hours. Tissue plasminogen activator (tPA, $4 \mathrm{mg}$ ) was added to the perfusate after one hour. The right kidney was pumped for 5 hours and the left kidney for 12 hours 35 minutes. The third kidney was recovered in our OPO and placed on machine perfusion after biopsy. Pump flows began at $71 \mathrm{~mL} / \mathrm{min}$ and increased over several hours to $110 \mathrm{~mL} / \mathrm{min}$. Tissue plasminogen activator $(4 \mathrm{mg})$ was added to the perfusate after one hour. The terminal resistive index (mean pressure/flow) was 0.20 prior to transplantation. The mate kidney was turned down regionally and nationally and discarded.

\section{Results}

3.1. Kidney Biopsies. Renal biopsies were obtained from the renal allograft at organ recovery, upon implantation (following machine perfusion), and 3 months after transplant. The donor biopsy originally showed $75-80 \%$ of the glomeruli contained fibrin thrombi (Figure 1(a)). Upon implantation (after machine perfusion), a wedge biopsy showed approximately $50 \%$ of the glomeruli with capillaries occluded by fibrin thrombi (Figure 1(b)). Biopsy of the kidney three months after transplantation in one of the recipients revealed no residual fibrin thrombi in glomeruli (Figure 2).

3.2. Recipient Outcomes. Kidneys from the first donor were transplanted separately. The first kidney functioned immediately, the second slowly and the third recipient suffered delayed graft function; none of the recipients experienced acute rejection. All three recipients had excellent renal allograft function after transplantation and long-term function remains excellent (Table 2 ).

\section{Discussion}

In order to expand the organ donor pool, many centers are now performing deceased donor kidney transplants with organs recovered from donors who would have been deemed unsuitable previously. This includes those donors with chronic renal damage (expanded criteria donors) as well as those with severe acute injury that may be reversible. Potential organ donors with DIC and renal dysfunction are one such category of marginal kidney donors that may prove satisfactory.

The majority of cases of DIC are characterized by laboratory abnormalities alone and the safety of using such kidneys has been established [6, 7]. However, DIC can lead 
TABLE 2: Recipient characteristics.

\begin{tabular}{lccccccc}
\hline & Age, gender & Etiology ESRD & CIT & \multicolumn{2}{c}{$\begin{array}{c}\text { Creatinine }(\mathrm{mg} / \mathrm{dL}) \\
7 \text { and 30 days }\end{array}$} & \multicolumn{2}{c}{$\begin{array}{c}\text { Creatinine }(\mathrm{mg} / \mathrm{dL}) \\
1 \text { and } 5 \text { years }\end{array}$} \\
\hline Recipient no. 1 & $38, \mathrm{M}$ & IDDM & $22 \mathrm{hr}$ & 1.8 & 1.4 & 1.4 & 1.8 \\
Recipient no. 2 & $34, \mathrm{M}$ & IDDM & $30 \mathrm{hr}$ & 4.6 & 1.3 & 1.3 & 1.6 \\
Recipient no. 3 & $34, \mathrm{M}$ & Hypertension & $24 \mathrm{hr}$ & 10.7 & 4.6 & 2.4 & 2.1 \\
\hline
\end{tabular}

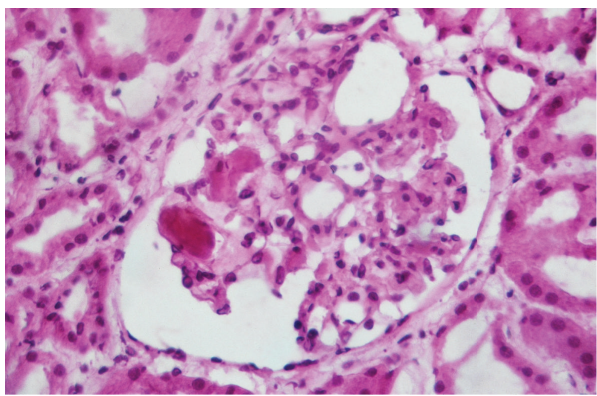

(a)

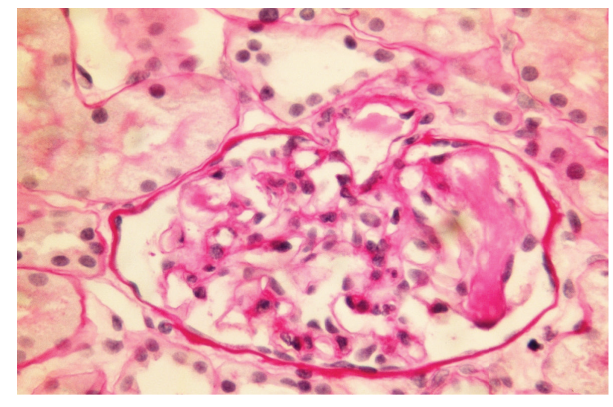

(b)

FiguRE 1: (a) Donor biopsy at organ procurement. Frozen section of the kidney showing several capillaries distended and filled by recent fibrin thrombi. Similar changes are seen in 75 to $80 \%$ of the glomeruli (H\&E, 25x). (b) Implantation biopsy (after machine perfusion). In recipient 1, after perfusion of tPA, a few thrombi are seen in some glomeruli; however, the number of affected tufts was less than 50\%. (H\&E, $25 x)$.

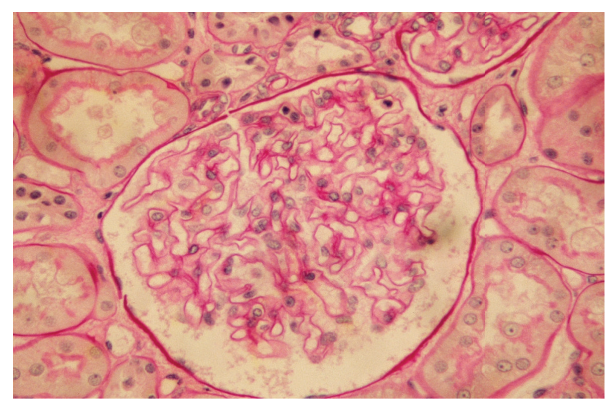

FIGURE 2: Follow-up (protocol) biopsy, taken 3 months after transplantation. A normal glomerulus with patent capillary loops and normal basement membrane is seen. No residual capillary thrombi are present. (H\&E stain, 25x).

to failure of multiple organs, including renal dysfunction due to intravascular (i.e., intraglomerular) deposition of fibrin. Often when significant renal dysfunction is present or a renal biopsy demonstrates microthrombi within the glomeruli, these kidneys are not utilized. Such was the circumstance in these cases as the donor kidneys were refused locally and by several centers in the national allocation. We accepted the allografts based on the favorable experience at Allegheny General Hospital utilizing tPA infusion $(30-50 \mathrm{mg}$ ) followed by cold storage [10]. We added machine perfusion as a means to both evaluate the kidneys through measure of resistive index and as means for infusing tPA.

Tissue plasminogen activator is a fibrinolytic agent that binds to fibrin in a thrombus and converts entrapped plasminogen to plasmin initiating local fibrinolysis. For the treatment of acute renal injury, tPA has been used experimentally to abrogate ischemia-reperfusion trauma [11] and clinically to treat renovascular thrombosis [12] and DIC secondary to meningococcemia [13]. These clinical applications took place in vivo at normal body temperatures. However, it is likely that tPA has similar effects well below 37 degrees $\mathrm{C}$ and even at the 4 degree $\mathrm{C}$ environment used in machine perfusion. In fact, while the rate of fibrin degradation is less pronounced at 25 degrees $\mathrm{C}$, no further decrease was noted at 10,0 , or -8 degrees $C$ [14]. Hence one can presume efficacy of the approach by Nghiem and colleagues who described ex vivo thrombolysis with $30-50 \mathrm{mg}$ of tPA during cold storage [10]. While those authors made no mention of renal dysfunction in any of the donors, repeat biopsies of 12 of 13 kidneys prior to transplantation showed complete resolution of fibrin thrombi. One kidney was lost ten days after transplantation due to thrombosis and the other 12 were functioning 24-48 months after transplantation with a mean creatinine of $1.8 \mathrm{mg} / \mathrm{dL}$. Preservation by machine perfusion was not reported in this or any previous study of donor DIC.

Renal allografts from donors with DIC, including those with renal dysfunction and evidence of microvascular thrombosis, can be used with good outcomes. Increased confidence is afforded through the use of young donors with suitable pulsatile perfusion parameters. Flushing the kidneys with tPA prior to transplantation might facilitate resolution of thrombi and should be considered in such cases. The finding of normal flows and resistive indices supported the utilization of the allografts in our cases. Serial biopsies demonstrated the reduction and eventual disappearance of glomerular fibrin deposits. Our experience and the few previous descriptions in the literature further support the safety of using these kidneys for transplantation. 


\section{References}

[1] M. S. Druskin and R. Drijansky, "Afibrinogenemia with severe head trauma," JAMA, vol. 219, no. 6, pp. 755-756, 1972.

[2] S. H. Goodnight, G. Kenoyer, S. I. Rapaport, M. J. Patch, J. A. Lee, and T. Kurze, "Defibrination after brain-tissue destruction: a serious complication of head injury," The New England Journal of Medicine, vol. 290, no. 19, pp. 1043-1047, 1974.

[3] M. Levi, "Disseminated intravascular coagulation: what's new?" Critical Care Clinics, vol. 21, no. 3, pp. 449-467, 2005.

[4] W. F. Baker, "Clinical aspects of disseminated intravascular coagulation: a clinician's point of view," Seminars in Thrombosis and Hemostasis, vol. 15, no. 1, pp. 1-57, 1989.

[5] F. B. Taylor, C. H. Toh, W. K. Hoots, H. Wada, and M. Levi, "Towards definition, clinical and laboratory criteria, and a scoring system for disseminated intravascular coagulation: on behalf of the scientific subcommittee on Disseminated Intravascular Coagulation (DIC) of the International Society on Thrombosis and Haematostasis (ISTH)," Thrombosis and Haemostasis, vol. 86, no. 5, pp. 1327-1330, 2001.

[6] T. R. Hefty, L. W. Cotterell, S. C. Fraser, S. H. Goodnight, and T. R. Hatch, "Disseminated intravascular coagulation in cadaveric organ donors. Incidence and effect on renal transplantation," Transplantation, vol. 55, no. 2, pp. 442-443, 1993.

[7] C. J. Wang, S. Shafique, J. McCullagh, D. A. Diederich, F. T. Winklhofer, and J. B. Wetmore, "Implications of donor disseminated intravascular coagulation on kidney allograft recipients," Clinical Journal of the American Society of Nephrology, vol. 6, no. 5, pp. 1160-1167, 2011.

[8] M. Pastural, B. Barrou, A. Delcourt, M. O. Bitker, S. Ourahma, and F. Richard, "Successful kidney transplantation using organs from a donor with disseminated intravascular coagulation and impaired renal function: case report and review of the literature," Nephrology Dialysis Transplantation, vol. 16, no. 2, pp. 412-415, 2001.

[9] A. M. Meyers, J. Lewin, P. B. Disler, F. J. Milne, P. Hyde, C. Abrahams et al., "Donor disseminated intravascular coagulation (DIC), intraglomerular fibrin deposition, and subsequent graft function," Kidney International, vol. 13, article 432, 1978.

[10] D. D. Nghiem, P. R. Olson, and K. K. Sureshkumar, "Role of pulsatile perfusion with tissue plasminogen activator in deceased donor kidneys with extensive glomerular thrombosis," Transplantation Proceedings, vol. 41, no. 1, pp. 29-31, 2009.

[11] J. J. T. H. Roelofs, K. M. A. Rouschop, J. C. Leemans et al., "Tissue-type plasminogen activator modulates inflammatory responses and renal function in ischemia reperfusion injury," Journal of the American Society of Nephrology, vol. 17, no. 1, pp. 131-140, 2006.

[12] D. Francois and B. Delgrange, "A case of acute renal failure caused by thrombosis of both renal arteries," Acta Clinica Belgica, vol. 49, no. 3-4, pp. 177-182, 1994.

[13] W. Zenz, B. Zoehrer, M. Levin et al., "Use of recombinant tissue plasminogen activator in children with meningococcal purpura fulminans: a retrospective study," Critical Care Medicine, vol. 32, no. 8, pp. 1777-1780, 2004.

[14] D. C. Rijken, E. Seifried, M. M. Barrett-Bergshoeff, and G. Dooijewaard, "Plasminogen activation at low temperatures in plasma samples containing therapeutic concentrations of tissue-type plasminogen activator or other thrombolytic agents," Thrombosis and Haemostasis, vol. 64, no. 1, pp. 47-52, 1990. 




The Scientific World Journal
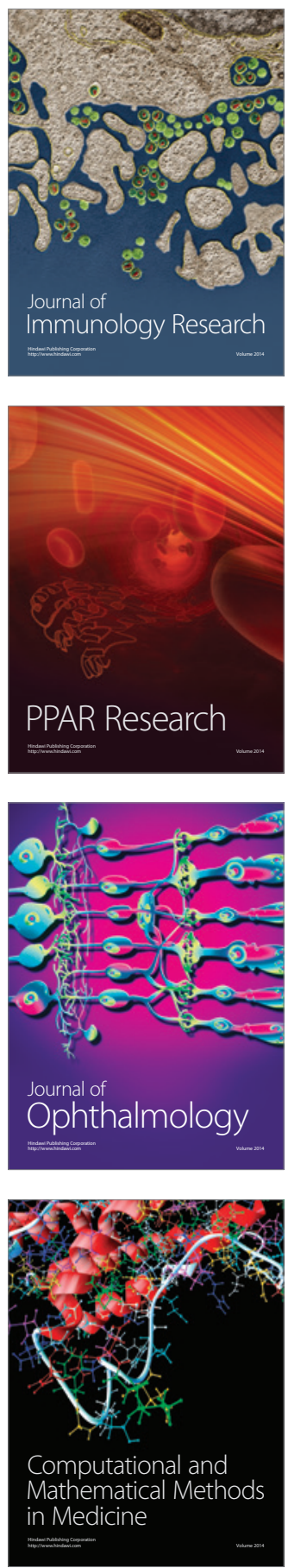



Gastroenterology

Research and Practice
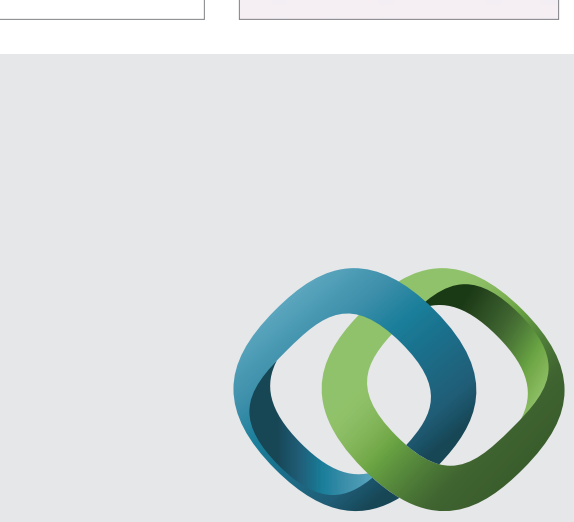

\section{Hindawi}

Submit your manuscripts at

http://www.hindawi.com
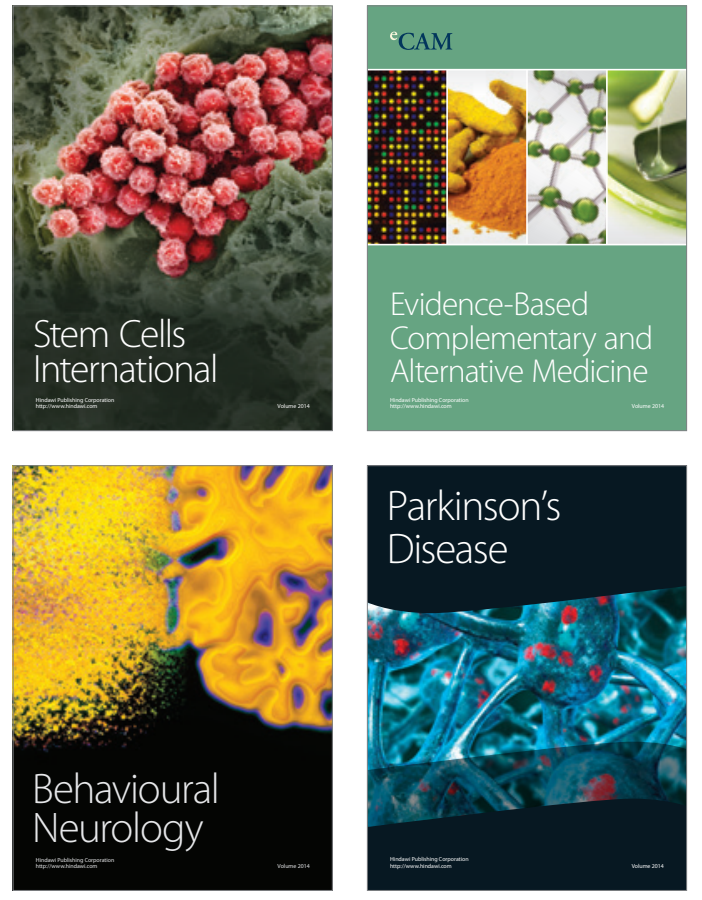
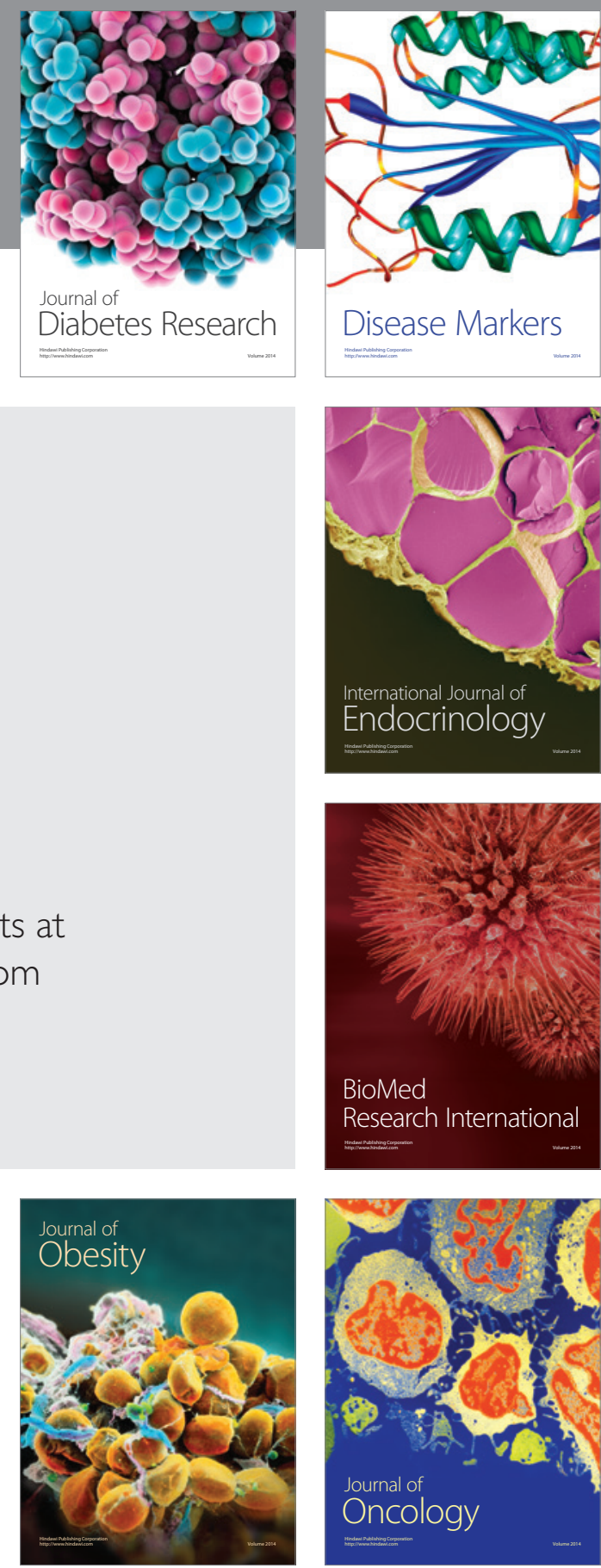

Disease Markers
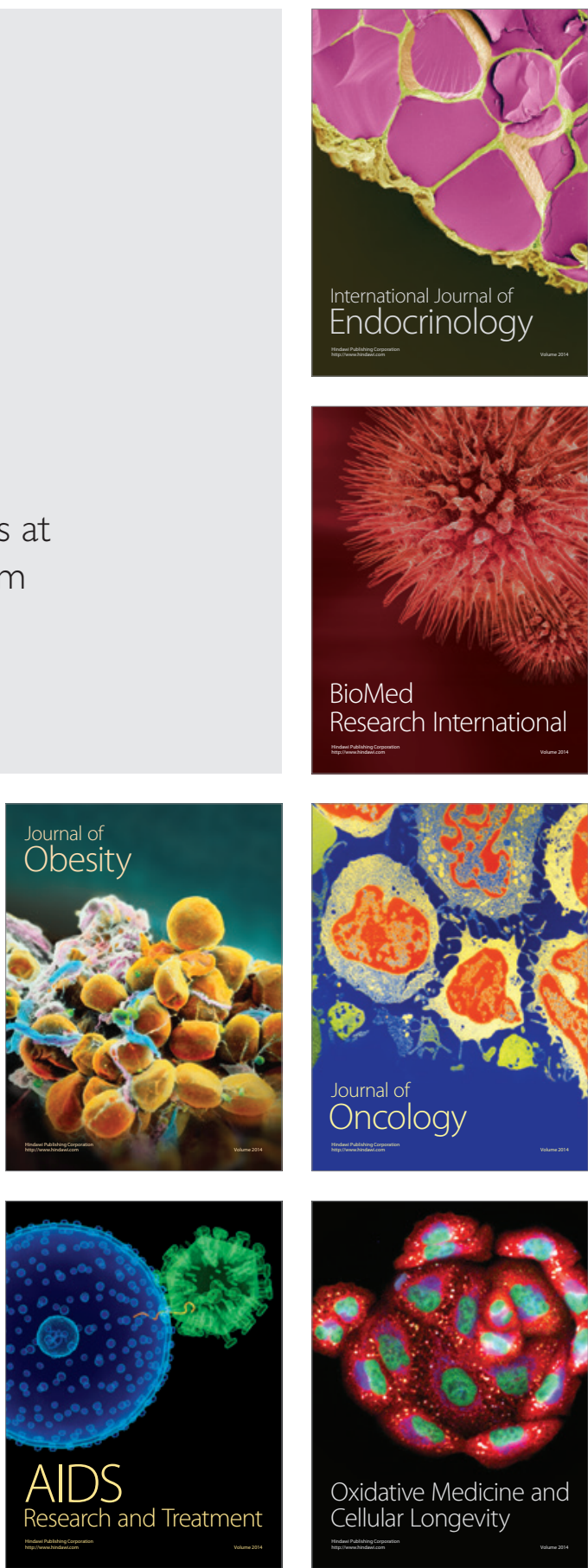